\title{
Trends in Gastrointestinal Cancer Mortality Rate in Hungary
}

\author{
Klaudia Farkas $^{1}$ • Mónika Szúcs ${ }^{2}$ - Tibor András Nyári ${ }^{2}$
}

Received: 11 August 2015 / Accepted: 7 March 2016

(C) Arányi Lajos Foundation 2016

\begin{abstract}
The aim of this study was to investigate the annual death trends for gastrointestinal cancer in Hungary between 1963 and 2012. Data on the numbers of cancer deaths were obtained from the published nationwide population register. Numbers of deaths from esophageal, gastric and colorectal cancer were available during the study period. However, the mortality data for hepatic, pancreatic and gallbladder cancer have been published only since 1979 . Joinpoint regression was applied to investigate the annual trends in the rates of cancer mortality. The annual mortality rates of gastric and gallbladder cancer decreased throughout the study period. Furthermore, declines in mortality from esophageal and hepatic cancers have been observed since 1998 and 1995, respectively. However, the rates of colorectal and pancreatic cancer mortality have been increasing in the past few years. Nevertheless, the mortality rates of colorectal and pancreatic cancers have increased in males aged 40-59 years during the study period. Moreover, significantly higher risks of gastrointestinal cancer-related deaths have been observed in males as compared with females except for death related to cancer of the gallbladder. The presented data suggest that the Hungarian mortality rates are particularly high. The detection of gastrointestinal cancers at an early stage would significantly improves the outcome of these malignancies.
\end{abstract}

Authors Klaudia Farkas and Mónika Szücs contributed equally to this work.

Tibor András Nyári

nyari.tibor@med.u-szeged.hu

$1 \quad 1$ st Department of Medicine, University of Szeged, Szeged, Hungary

2 Department of Medical Physics and Informatics, University of Szeged, P.O. Box: 427, Szeged H-6701, Hungary
Keywords Colorectal cancer · Cancer of the gallbladder . Esophageal cancer · Gastric cancers · Hepatic cancer . Pancreatic cancer · Mortality rates · Trend · Epidemiology . Hungary

\section{Introduction}

Colorectal cancer is the third most common cancer worldwide in men and the second most common in women, with 1.3 million new cases every year [1]. Gastrointestinal cancers are common in both genders in Hungary, accounting for 10, 878 deaths ( $34.4 \%$ of all cancer deaths) in the country in 2012 [2]. The Hungarian mortality rates for colorectal and pancreatic cancer were the highest and the second highest among men in Europe in 2012, respectively [3]. Moreover, higher mortality rates were also reported for gallbladder, esophageal and liver cancer in Hungary than in other members countries of the European Union [3, 4].

The worldwide rank of Hungarian mortality rate from cancer was 19th in 2008 [5], which was slightly better than in the mid-1990s [6, 7].

The trends of annual mortality rates of gastrointestinal cancers overall or broken down by gender have not been investigated in a complex manner in Hungary: only descriptive annual mortality rates of gastrointestinal cancers have been reported, and there have been no publications on trends (especially segmented linear trends) by gender or age groups.

The aim of the epidemiological study reported here was to investigate the trends in the annual Hungarian mortality rates from gastrointestinal cancers and to estimate the risk of mortality by gender through the use of statistically internationally comparable risk measurements of the patterns of mortality from gastrointestinal cancers in Hungary. 


\section{Material and Methods}

\section{Study Population}

Two periods were considered in the analyses. Data on the numbers of population and deaths from esophageal, gastric and colorectal cancer were available between 1 January 1963 and 31 December 2012 from the published nationwide population registry of the Hungarian Central Statistical Office [2]. Mortality data on hepatic, pancreatic and gallbladder cancer have been published since 1979, and thus the period between 1 January 1979 and 31 December 2012 was used in the analyses [2].

The data concerning the cause of deaths are published annually by the Central Statistical Office. Although the International Classification of Diseases (ICD) coding has changed, mortality data on all of the above-detailed gastrointestinal cancers were published during the study period.

The ICD-10 codes were applied to classify the following categories of malignant neoplasms of digestive organs in the study: malignant neoplasms of the esophagus (C15), stomach (C16), colorectum (C18-21), liver (C22), gallbladder (C23) and pancreas (C25).

Data on both the numbers of the population and the numbers of cancer-related deaths were classified by age groups as follows: 0-14 years, $15-39$ years, $40-59$ years, 60-69 years, 70-79 years and over 80 years or above. Thus, agestandardized mortality rates (ASMRs) per 100,000 personyears were calculated, using the standard world population for comparison.

Since the numbers of deaths in the group aged 0-14 years were too small, all analyses were carried out with the omission of this group.

\section{Statistical Methods}

\section{Investigation of Annual Trends}

The ASMRs were used to investigate trends in mortality rates for gastrointestinal cancers in Hungary during the study period.

Trends were investigated using negative binomial regression models in analyses by gender, age group and type of gastrointestinal cancer. Relative risks (RRs) and $95 \%$ confidence intervals $(95 \%$ CIs) were calculated. Joinpoint (JP) regression analyses were additionally applied to characterize trends and to find turning points during the study periods. JP analyses were performed with the joinpoint regression software (version 4.0.4) from the Surveillance Research Program of the US National Cancer Institute.

The $p$-values less than 0.05 were considered to be statistically significant. All analyses were carried out with STATA Software version 9.0 (Stata Corp LP, College Station, Texas, USA).

\section{Results}

Overall, 23,164 esophageal, 159,265 gastric, 193,432 colorectal, 31,526 liver, 32,015 gallbladder and 52,361 pancreatic cancer-related deaths were registered in Hungary during the study period. Colorectal cancer was the most common cause of death (Table 1) and the highest ASMR of 25.01 per 100,000 persons-years (95\%CI 24.89-25.13) was also detected in case of colorectal cancer (Table 1). Table 1 summarizes the ASMRs of gastrointestinal cancers overall and by gender during the study period. The ASMRs of esophageal, gastric, colorectal, liver, gallbladder and pancreatic cancers in 2012 were $7.83,20.27$, $58.03,10.15,6.59$ and 22.29 per 100,000 persons per year, respectively (Fig. 1a-f).

The highest ASMRs of gastrointestinal cancers were observed in the group between the age of 70 and 79 except for the mortality rates of esophageal cancer being the highest in the group aged 40-59 years (Table 1). However, high mortality rates of gastric, colorectal and pancreatic cancer were found in groups aged 4059 years and 60-69 years which were more marked in males (Table 1).

Furthermore, significantly higher risks of deaths from gastrointestinal cancer were detected in males as compared with females in all types of cancers except death from cancer of the gallbladder. The estimated risks of mortality for male cases with $95 \%$ CIs are given in Table 2. Risk estimates of deaths from gastrointestinal cancer highlighted a more than twice as great a risk in males than in females for hepatic and gastric cancers and a more than seven-fold risk for esophageal cancer.

\section{Mortality Rates and Annual Trends Between 1963 and 2012}

The average ASMRs of esophageal cancer varied between 3.11 (1973) and 11.41 (1998) in the population older than 14 years between the period 1963-2012 (Fig. 1a). Overall, the JP regression model fitted a segmented line indicating two main changes in the trend: after a small decrease in the period between 1963 and 1971 a peak was observed in 1998 and then a significant decrease was monitored. A significantly increasing linear trend followed the decrease between 1963 and 1971 in the mortality with a break point in 1990 yielding two periods as 1971-1990 and 1990-1998, and then a significant decline between 1998 and 2012 (the slopes of the four segments: $-0.03(p=0.02),-0.06$ $(p<0.001), 0.02(p=0.002)$ and $-0.02(p<0.001)$, respectively. Similar trends were observed among men in the gender-specific analyses, but in women between two basically constant periods a significant increase was 
Table 1 The number of deaths and the age-standardized mortality rates overall and by gender in Hungary during the study period

\begin{tabular}{|c|c|c|c|c|c|c|c|}
\hline & & \multicolumn{3}{|l|}{ 1963-2012 } & \multicolumn{3}{|l|}{ 1979-2012 } \\
\hline & & $\begin{array}{l}\text { Esophegal } \\
\text { cancer }\end{array}$ & $\begin{array}{l}\text { Gastric } \\
\text { cancer }\end{array}$ & $\begin{array}{l}\text { Colorectal } \\
\text { cancer }\end{array}$ & $\begin{array}{l}\text { Hepatic } \\
\text { cancer }\end{array}$ & $\begin{array}{l}\text { Cancer of } \\
\text { gallbladder }\end{array}$ & $\begin{array}{l}\text { pancreatic } \\
\text { cancer }\end{array}$ \\
\hline \multirow[t]{11}{*}{ OVERALL } & & Number & of deaths & & Number & of deaths & \\
\hline & & 23,164 & 159,265 & 193,432 & 31,526 & 32,015 & 52,361 \\
\hline & Age & & & & & & \\
\hline & $0-14$ & 0.00 & 0.01 & 0.01 & 0.02 & 0.00 & 0.00 \\
\hline & $15-39$ & 0.06 & 0.48 & 0.58 & 0.10 & 0.03 & 0.13 \\
\hline & $40-59$ & 1.65 & 4.60 & 5.25 & 1.09 & 0.69 & 1.86 \\
\hline & $60-69$ & 0.89 & 5.60 & 6.30 & 1.16 & 1.01 & 1.82 \\
\hline & $70-79$ & 0.49 & 6.32 & 7.48 & 1.17 & 1.32 & 1.89 \\
\hline & $80+$ & 0.22 & 3.66 & 5.39 & 0.63 & 1.00 & 1.21 \\
\hline & ASMR & 3.31 & 20.67 & 25.01 & 4.16 & 4.05 & 6.89 \\
\hline & $95 \% \mathrm{CI}$ & $3.27-3.35$ & $20.57-20.77$ & $24.89-25.13$ & $4.12-4.20$ & $4.01-4.09$ & $6.83-6.95$ \\
\hline \multirow[t]{11}{*}{ Male } & & Number & of deaths & & Number & of deaths & \\
\hline & & 19,486 & 94,075 & 98,899 & 19,068 & 8752 & 26,627 \\
\hline & Age & & & & & & \\
\hline & $0-14$ & 0.00 & 0.01 & 0.02 & 0.02 & 0.00 & 0.00 \\
\hline & $15-39$ & 0.10 & 0.53 & 0.62 & 0.12 & 0.03 & 0.16 \\
\hline & $40-59$ & 3.07 & 6.50 & 6.34 & 1.60 & 0.51 & 2.52 \\
\hline & $60-69$ & 1.76 & 8.53 & 8.29 & 1.79 & 0.69 & 2.35 \\
\hline & $70-79$ & 1.02 & 9.38 & 9.84 & 1.76 & 0.90 & 2.26 \\
\hline & $80+$ & 0.43 & 5.11 & 6.75 & 0.81 & 0.70 & 1.30 \\
\hline & ASMR & 6.38 & 30.05 & 31.85 & 6.10 & 2.83 & 8.60 \\
\hline & $95 \% \mathrm{CI}$ & $6.28-6.48$ & $29.85-30.25$ & $31.83-31.87$ & $6.02-6.18$ & $2.77-2.89$ & $8.50-8.70$ \\
\hline \multirow[t]{11}{*}{ Female } & & Number & of deaths & & Number & of deaths & \\
\hline & & 3678 & 6,5190 & 94,533 & 12,458 & 23,263 & 25,734 \\
\hline & Age & & & & & & \\
\hline & $0-14$ & 0.00 & 0.01 & 0.01 & 0.01 & 0.00 & 0.00 \\
\hline & $15-39$ & 0.01 & 0.43 & 0.54 & 0.08 & 0.03 & 0.09 \\
\hline & $40-59$ & 0.36 & 2.86 & 4.26 & 0.63 & 0.86 & 1.25 \\
\hline & $60-69$ & 0.22 & 3.33 & 4.76 & 0.68 & 1.26 & 1.40 \\
\hline & $70-79$ & 0.17 & 4.41 & 5.99 & 0.78 & 1.58 & 1.65 \\
\hline & $80+$ & 0.12 & 2.98 & 4.75 & 0.55 & 1.14 & 1.16 \\
\hline & ASMR & 0.88 & 14.02 & 20.31 & 2.73 & 4.88 & 5.56 \\
\hline & $95 \% \mathrm{CI}$ & $0.86-0.90$ & $13.90-14.14$ & $20.17-20.45$ & $2.67-2.79$ & $4.82-4.94$ & $5.48-5.64$ \\
\hline
\end{tabular}

detected between 1984 and 2000 with a slope of 0.05 $(p<0.001)$ (Fig. 2a).

A decreasing trend was observed with four segments in ASMRs of gastric cancer which were as follows: 1963-1978 (slope: $-0.018, p<0.001$ ), 1978-1986 (slope: -0.044 , $p<0.001$ ), 1986-1990 (slope: 0.003, $p=.90$ ) and 19902012 (slope: $-0.036, p<0.001$ ) (Fig. 1b). Although, the mortality rates were significantly higher in males than in females, they decreased significantly between 1963 and 2012 (Fig. 2b). Moreover, the mortality rates revealed also a decreasing pattern in all age groups during the study period.
In the mortality rates of colorectal cancer, a significant, approximately $3 \%$ annual increase was revealed until 1978 and a $1.5 \%$ increase was then observed until the peak in 1998, followed by a significant decrease until 2006, and a basically constant period thereafter (Fig. 1c). The annual changes in the percentages, the slopes with $p$ values of each segment were $3.17 \%, 0.03(p<0.001) ; 1.49 \%, 0.01(p<0.001), 1.51 \%$, $-0.02(p<0.001)$ and $0.36 \%, 0.04(p=0.48)$, respectively. Similar trends were observed in the male mortality rates for colorectal cancer (Fig. 2c). However, the female mortality rates of colorectal cancer increased until 1997 and then 

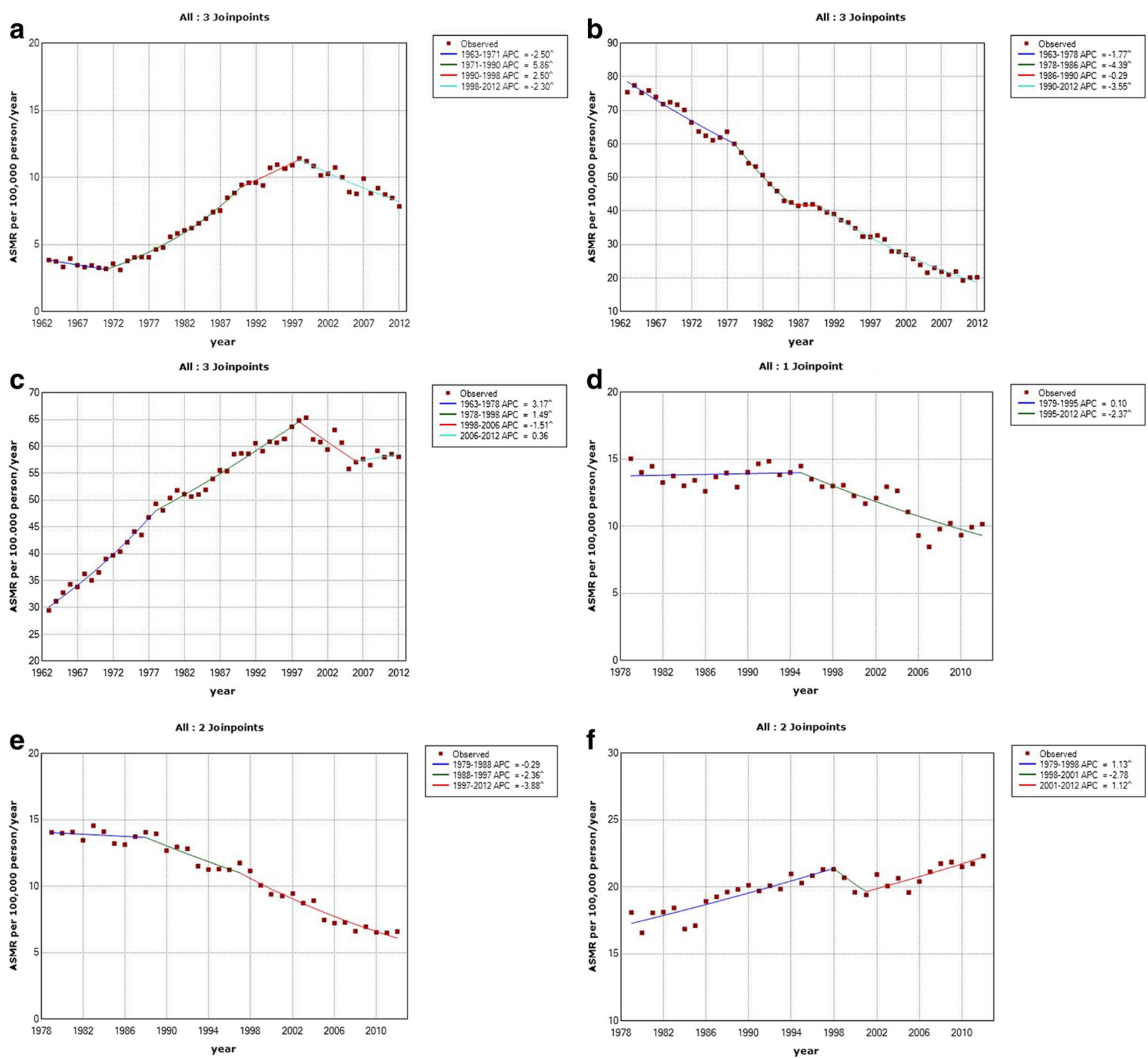

Fig. 1 Results of fitted segmented lines of annual Hungarian age-standardized mortality rates for esophageal cancer $\mathbf{a}$, gastric cancer $\mathbf{b}$, colorectal cancer $\mathbf{c}$, hepatic cancer $\mathbf{d}$, cancer of the gallbladder $\mathbf{e}$ and pancreatic cancer $\mathbf{f}$ using joinpoint regression models

decreased with relative constancy from 23.5 to 19.6 between 1998 and 2012 (Fig. 2c). Moreover, a significant increase in the

Table 2 Risk of mortality from gastrointestinal cancers in male groups as compared with females

\begin{tabular}{lcc}
\hline & Risk & 95 \% confidence interval \\
\hline Esophageal cancer & 7.25 & $5.29-9.96$ \\
Gastric cancer & 2.07 & $1.90-2.26$ \\
Colorectal cancer & 1.55 & $1.43-1.68$ \\
Hepatic cancer & 2.28 & $1.85-2.80$ \\
Cancer of the gallbladder & 0.58 & $0.47-0.72$ \\
Pancreatic cancer & 1.60 & $1.37-1.86$ \\
\hline
\end{tabular}

mortality rates from 3.53 per 100,000 persons to 8.56 per 100 , 000 persons was detected in males aged $40-59$ years throughout the period 1963-2012 with a slope of $0.01(p<0.001)$.

\section{Mortality Rates and Annual Trends Between 1979 and 2012}

In the analyses of mortality rates of hepatic cancer, the JP regression depicted a basically constant period between 1979 and 1995, which was followed by a significant decrease in mortality rates. The slopes of the segmented linear were $0.00(p=0.77)$ and $-0.02(p<0.001)$, respectively (Fig. 1d). A similar trend was observed in both male and female mortality rates for hepatic cancer (Fig. 2d). 

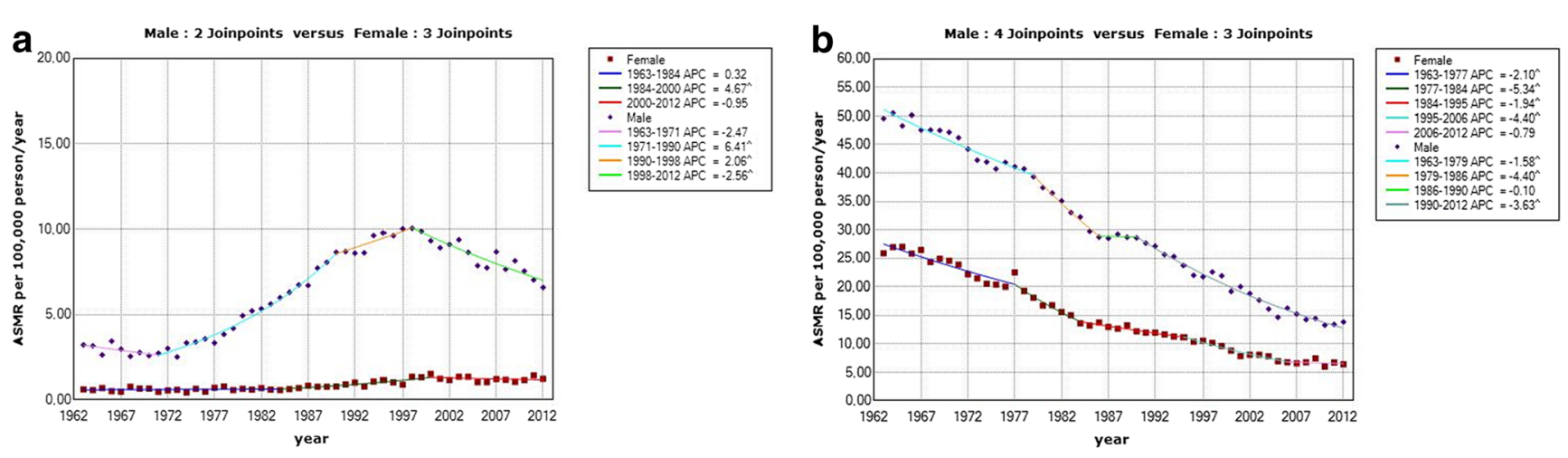

C
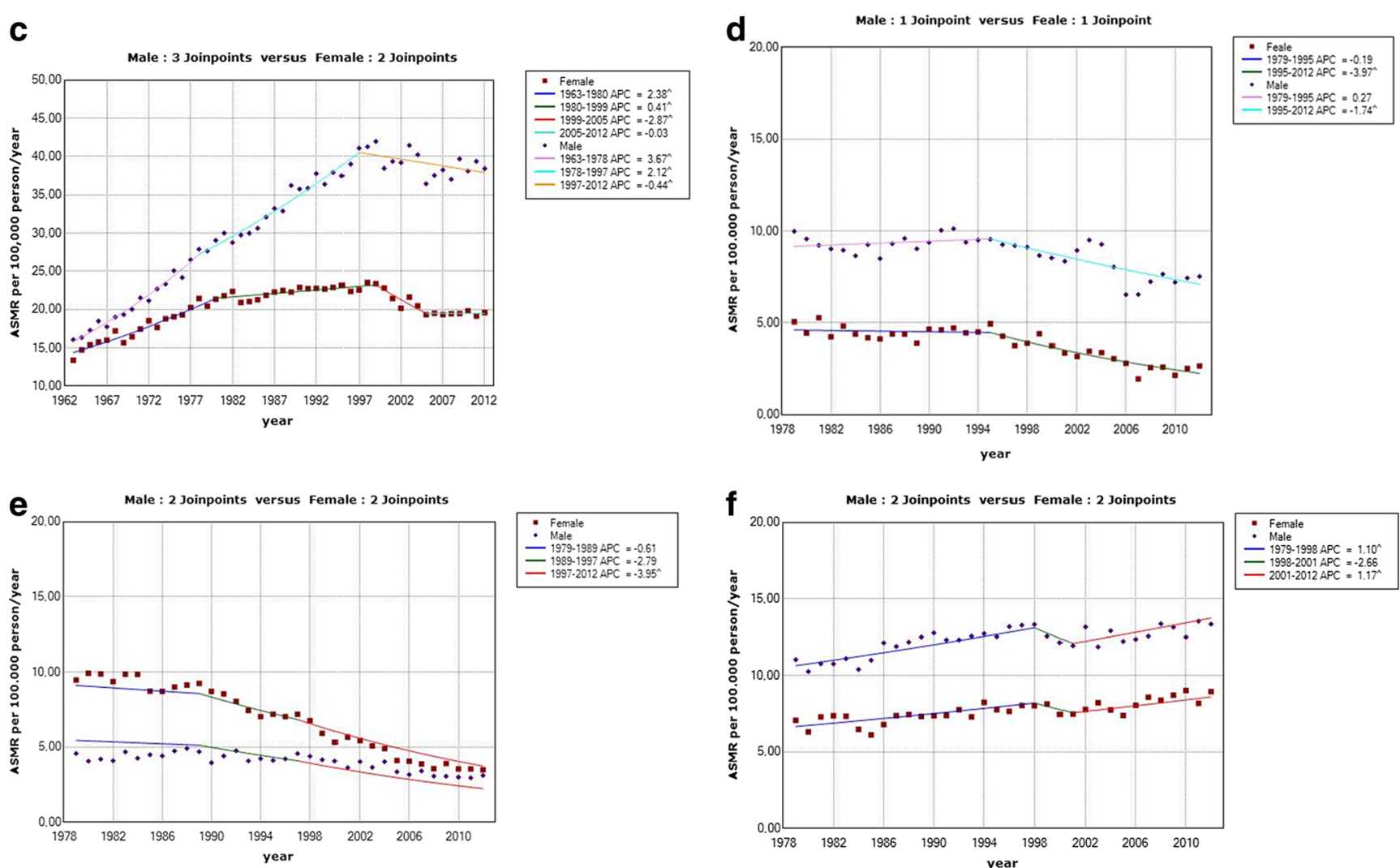

Fig. 2 Gender-specific results of fitted segmented lines of annual Hungarian age-standardized mortality rates for esophageal cancer $\mathbf{a}$, gastric cancer $\mathbf{b}$, colorectal cancer $\mathbf{c}$, hepatic cancer $\mathbf{d}$, cancer of the gallbladder $\mathbf{e}$ and pancreatic cancer $\mathbf{f}$ using joinpoint regression models

The overall mortality rates of cancer of the gallbladder remained unchanged until 1988. Since then significant decreasing trends have been observed with slopes of -0.02 $(p<0.001)$ and $0.04(p<0.001)$ in the periods of 19881997 and 1997-2012, respectively (Fig. 1e). Similar changes were detected in the gender-specific analyses, which depicted turning points in 1989 and 1997 for females and in 1988 and 1998 for males, and changes in segmented linear trends (Fig. 2e). The slopes of the segments in the female cases were $-0.01(p<0.07)$ for 1979-1989, $-0.04(p<0.001)$ for 19891997 and $-0.05(p<0.001)$ for 1997-2012, and in the male cases were $0.01(p=0.28)$ for 1979-1988, $-0.01(p=0.32)$ for 1988-1997 and $-0.03(\mathrm{p}=<0.001)$ for 1997-2012.
There was an increasing trend in the mortality rates of pancreatic cancer between 1979 and 2012, but the JP regression model fitted a non-significantly decrease between 1998 and 2001, indicating a significantly increasing linear trend from 1979 to 1998 , and then a rather non-constant level between 1998 and 2001, followed by a significant increase from 2001 to 2012 (the slopes of the three segments: 0.01 $(p<0.001),-0.03(p=0.53)$ and $0.01(p<0.001)$, respectively; Fig. 1f). Very similar trends in mortality rates of pancreatic cancer were found in the gender-specific analyses for both female and male cases (Fig. 2f). Furthermore, a significant increase in mortality rate from 2.70 per 100,000 persons to 4.25 per 100,000 persons was detected in males aged 40 
59 years throughout the period 1979-2012, with a slope of $0.01(p<0.001)$.

\section{Discussion}

\section{Main Findings}

The mortality rate of colorectal cancer was revealed in a significant annual increase until 1998, followed by a significant decrease until 2006, and a basically constant period thereafter and an increasing trend in the mortality rate of pancreatic cancer was observed during the whole study period. However, the mortality risks of colorectal and pancreatic cancers increased in males aged 40-59 years during the study period as compared with other age groups. Similarly, increasing mortality esophageal and the other gastrointestinal cancers were found in the groups aged 40-59 years and 70-79 years relative to the other age groups, respectively. Nevertheless, significantly higher risks of gastrointestinal cancer-related deaths were observed in males as compared with females except death related to cancer of the gallbladder.

The annual mortality rates of gastric and gallbladder cancer decreased throughout the study period. Furthermore, a decline in mortality from esophageal and hepatic cancers was found since 1998 and 1995, respectively. However, our results revealed that the mortality rates of colorectal and pancreatic cancer have been increasing in the past few years. Summarizing, our study describes the pattern of trends in mortality rates of gastointestinal cancers in Hungary during the study period.

\section{Strengths and Limitations}

Instead of reporting only the ASMRs, we applied regression models to estimate the trends in the mortality rates of gastrointestinal cancers in Hungary between 1963 and 2012, including JP regression, which involves the best fit of the segmented lines connected at the "joinpoints" (turning points) through use of a Poisson model of variation [8]. As far as we know, this was the first utilization of JP regression to investigate the pattern of trends in gastrointestinal cancers in Hungary.

Although ASMRs of gastrointestinal cancers in Hungary have been investigated previously, detailed statistics have been only reported rarely.

We also estimated the risk of gastrointestinal cancer-related death by using population data. Due to the lack of available data, only gender-specific analyses were investigated. However, this study investigated a 50 -year period, which is one of the longest study periods subjected to the analysis of trends in cancer mortality of the digestive organs.

Data were obtained from civil registers, which could have been influenced by a certain simplification of categorization during the 50-year interval of the study, but we are confident that our results do reflect real trends.

\section{Comparison with Other Studies}

A number of studies have been reported to investigate trends in cancer incidence and mortality in different geographical areas [9-11]. Furthermore, in most countries, trends in total cancer mortality were more favorable in middle-aged populations than in Hungary.

Similarly to other studies, our findings confirm declines in gastric, esophageal and gallbladder cancer mortality, and increases in pancreatic and colorectal cancer mortality $[12,13]$.

Levi et al. reported age-standardized mortality rates per $100,000 \mathrm{men} /$ women for selected cancers in the 17 member countries of the European Union and the eight acceding countries in 2000 [12]. Although all central and eastern accession countries had exceedingly high rates, ranking from 1 to 8 , the Hungarian total mortality rate was the highest in men and the second highest in women. Nevertheless, the Hungarian mortality rates of $8.58,33.51$ and 10.74 per 100,000 men from esophageal, colorectal and pancreas cancers were the highest among the 25 countries, respectively.

Colorectal cancer is the second most common cause of cancer mortality in men worldwide and in Hungary [5, 14]. Similarly to other studies $[5,6,14]$, we found a significantly higher risk of colorectal cancer mortality in males, which was more marked in the group aged 40-59 years. Colorectal cancer is one of the most preventable of cancers if competent screening is used. The results of one study demonstrated a strong linear relationship between the country-specific mortality-to-incidence ratio (MIR) for colorectal cancer and health system ranking in all Organization for Economic Cooperation and Development (OECD) countries [15] and Hungary was ranked top both in the incidence rate and in the mortality rate of colorectal cancer in 2012. Nevertheless, countries with an MIR below the predicted MIR appear to be more likely to have formal colorectal cancer screening guidelines that are acted on across a variety of health care settings. Mortality rates from colorectal cancer were higher in Czech Republic than in Hungary at the beginning of the 21st century, but the Czech mortality rate decreased significantly during the decade after the screening of fecal immunochemical testing and fecal occult blood testing were introduced [15].

Gastric cancer is the fourth most common malignant tumor in Hungary [16]. The gastric cancer mortality rate is also high, but not the highest among the countries in the European Union. The reported mortality rates were higher in the Baltic states, Croatia and Portugal than in Hungary in 2009 [17]. In spite of the decrease revealed in this study, considerable educational and socioeconomic inequalities were reported in cancer mortality, particularly for gastric cancer among males [18]. Moreover, further declines in gastric cancer mortality rates 
may be achieved with through the control of the known risk factors, including Helicobacter pylori infection, tobacco consumption and diet [19].

Pancreatic cancer ranks the fifth and sixth most common cancer in men and women, respectively, and has the lowest 5year survival rate of any gastrointestinal tumor [4, 20]. Advancing age is a risk factor for pancreatic cancer, with $80 \%$ of cases occurring in patients 60 to 80 years of age. However, pancreatic cancer-related mortality has been increasing in Hungary since 2001 and 1979 overall and in males aged 40-59 years, respectively. Nevertheless, the Hungarian pancreatic cancer mortality rate was also ranked top in the countries of the European Union in 2012 [12].

An increase in the incidence of esophageal cancer has been reported in some European countries [4, 21, 22], though a decline in the mortality from esophageal cancer was observed in our study. However, in spite of the favorable decline in mortality rates from esophageal cancer in Hungary, the agestandardized mortality rates at all ages and truncated at 25-49 and 35-64 years are still ranked first in the member countries of the European Union during the period 2000-2009 [23].

Gallbladder cancer is one of the few malignancies that is more common in females than in males [11, 24]. However, in spite of the favorable decline in mortality rates from cancer of the gallbladder in Hungary, the age-standardized mortality rates are still ranked high in the member countries of the European Union during the period 2000-2009 [4].

International variation in liver cancer rates is largely explained by the distribution of chronic hepatitis $\mathrm{B}$ virus (HBV) and hepatitis $\mathrm{C}$ virus (HCV) infections and these two viruses account for $78 \%$ (HBV, $53 \%$; HCV, $25 \%$ ) of the total liver cancer deaths globally. $[5,25]$ Liver cancer is much more common in males than in females, and the liver cancer incidence rates for both men and women increased significantly from 1993 to 2002 in the economically developed countries of Western Europe [26]. In contrast, the mortality rates of hepatic cancer have been decreasing in both males and females in Hungary since 1995 and became lower than the average mortality rate of liver cancer in the European Union in 2012 [4].

\section{Conclusions}

Gastrointestinal cancers are global health problem with unacceptably high mortality due to the advanced state of most of the cases at diagnosis. The presented data suggest that Hungarian mortality rates are particularly high. The detection of gastrointestinal cancers at an early stage would significantly improve the outcome of these malignancies. The goal of cancer screening is to reduce mortality through a reduction in the incidence of the advanced disease. Colorectal cancer is a good candidate for screening, because it has detectable premalignant lesions, and early treatment is beneficial. Although some non-invasive methods are routinely used to screen for colorectal cancer, endoscopy still remains the most sensitive method for the detection of early lesions [27]. Despite advances in screening and early detection of some gastrointestinal cancers, no reliable screening test exists for most of them. Continued efforts are therefore needed to discover effective tests to identify patients with nonhereditary risk factors and to develop invasive and cost-effective screening modalities.

Acknowledgments Mónika Szücs is supported by the European Union and the State of Hungary, co-financed by the European Social Fund in the framework of TÁMOP-6.1.5/14/1-KONV-2015-0073 'National Excellence Program'.

\section{Compliance with ethical standards}

Conflict of interest The authors declare that they have no conflict of interest.

\section{References}

1. Allemani C, Weir HK, Carreira H, Harewood R, Spika D, Wang XS, et al. (2015) Global surveillance of cancer survival 1995-2009: analysis of individual data for $25,676,887$ patients from 279 population-based registries in 67 countries (CONCORD-2). Lancet 385(9972):977-1010

2. The Hungarian Central Statistical Office. Demographic Yearbook (1963-2012) Budapest. KSH 2013

3. Ferlay J, Steliarova-Foucher E, Lortet-Tieulent J, Rosso S, Coebergh JW, Comber H, Forman D, Bray F (2013) Cancer incidence and mortality patterns in Europe: estimates for 40 countries in 2012. Eur J Cancer 49:1374-1403

4. Bosetti C, Bertuccio P, Malvezzi M, Levi F, Chatenoud L, Negri E, La Vecchia C (2013) Cancer mortality in Europe, 2005-2009, and an overview of trends since 1980. Ann Oncol 24:2657-2671

5. Jemal A, Center MM, DeSantis C, Ward EM (2010) Global Patterns of Cancer Incidence and Mortality Rates and Trends. Cancer Epidemiol Biomark Prev 19:1893-1907

6. Szabolcs O (2003) Cancer epidemiology in Hungary and the Béla Johan National Program for the decade of health. Pathol Oncol Res 9:126-130

7. Péter A (2013) Connection between cancer- and alcohol-related mortality in a rural practice of a South-Hungarian village. Orv Hetil 154:700-706

8. Kim HJ, Fay MP, Feuer EJ, Midthune DN (2000) Permutation tests for joinpoint regression with applications to cancer rates. Stat Med 19:335-351

9. Jemal A, Bray F, Center MM, Ferlay J, Ward E, Forman D (2011) Global cancer statistics. CA Cancer J Clin 61:69-90

10. Spallek J, Arnold M, Razum O, Juel K, Rey G, Deboosere P, Mackenbach JP, Kunst AE (2012) Cancer mortality patterns among Turkish immigrants in four European countries and in Turkey. Eur J Epidemiol 27:915-921

11. Randi G, Franceschi S, La Vecchia C (2006) Gallbladder cancer worldwide: geographical distribution and risk factors. Int J Cancer 118:1591-1602

12. Levi F, Lucchini F, Negri E, La Vecchia C (2004) Trends in Mortality from Major Cancers in The European Union, Including Acceding Countries, in 2004. Cancer 101:2843-2850 
13. Ferlay J, Soerjomataram I, Dikshit R, Eser S, Mathers C, Rebelo M, et al. (2015) Cancer incidence and mortality worldwide: sources, methods and major patterns in GLOBOCAN 2012. Int J Cancer 136:E359-E386

14. Bosetti C, Levi F, Rosato V, Bertuccio P, Lucchini F, Negri E, La Vecchia C (2011) Recent trends in colorectal cancer mortality in Europe. Int J Cancer 129:180-191

15. Sunkara V (2015) Hébert JR. The colorectal cancer mortality-toincidence ratio as an indicator of global cancer screening and care Cancer 121:1563-1569

16. L1 H, Tulassay Z (2010) Epidemiology of gastrointestinal and liver tumors. Eur Rev Med Pharmacol Sci 14:249-258

17. Ferro A, Peleteiro B, Malvezzi M, Bosetti C, Bertuccio P, Levi F, Negri E, La Vecchia C, Lunet N (2014) Worldwide trends in gastric cancer mortality (1980-2011), with predictions to 2015, and incidence by subtype. Eur J Cancer 50:1330-1344

18. de Vries E, Arroyave I, Pardo C, Wiesner C, Murillo R, Forman D, Burdorf A, Avendaño M (2015) Trends in inequalities in premature cancer mortality by educational level in Colombia, 1998-2007. J Epidemiol Community Health 69:408-415

19. Karimi P, Islami F, Anandasabapathy S, Freedman ND, Kamangar F (2014) Gastric cancer: descriptive epidemiology, risk factors, screening, and prevention. Cancer Epidemiol Biomark Prev 23: 700-713

20. AEl S, RA D'A Jr, RA B, DC S (2003) International variation in pancreatic cancer mortality for the period 1955-1998. Eur J Epidemiol 18:801-816
21. AAl B, LJ S, Volovics A, Dorant E, Den Brandt PA v (2000) Trends in incidence of adenocarcinoma of the oesophagus and gastric cardia in ten European countries. Int J Epidemiol 29:645-654

22. Kroep S, Lansdorp-Vogelaar I, Rubenstein JH, Lemmens VE, van Heijningen EB, Aragonés N, van Ballegooijen M, Inadomi JM (2014) Comparing trends in esophageal adenocarcinoma incidence and lifestyle factors between the United States, Spain, and the Netherlands. Am J Gastroenterol 109: 336-343 quiz 335, 344

23. Cl C, Bosetti C, Malvezzi M, Bertuccio P, Levi F, Negri E, La Vecchia C, Lunet N (2014) Patterns and trends in esophageal cancer mortality and incidence in Europe (1980-2011) and predictions to 2015. Ann Oncol 25:283-290

24. Bjerregaard JK, Mortensen MB, Pfeiffer P, Academy of Geriatric Cancer Research (AgeCare) (2016) Trends in cancer of the liver, gall bladder, bile duct, and pancreas in elderly in Denmark, 1980 2012. Acta Oncol 55(Suppl 1):40-45

25. Bosch FX, Ribes J, Díaz M, Cléries R (2004) Primary liver cancer: worldwide incidence and trends. Gastroenterology 127(5 Suppl 1): S5-S16 Review

26. Center MM, Jemal A (2011) International trends in liver cancer incidence rates. Cancer Epidemiol Biomark Prev 20:2362-2368

27. Döbrőssy L, Kovács A, Budai A, Simon J, Horváth AR, Cornides A, Tulassay Z (2011) Controversial issues in colorectal screening in Hungary: conflict of clinical and public health viewpoints. Orv Hetil 152:1223-1232 